www.jmscr.igmpublication.org

Impact Factor 5.244

Index Copernicus Value: 5.88

ISSN (e)-2347-176x ISSN (p) 2455-0450

crossref DOI: _http://dx.doi.org/10.18535/jmscr/v4i4.24

\title{
Thrombophilia Gene Mutations in Relation to Recurrent Miscarriage
}

\author{
Authors \\ Dina, Medhat Shalaby ${ }^{1}$, Tawfik, Abdel Salam Tawfik ${ }^{2}$, Tarek, Abdel Zaher Karkour ${ }^{3}$ \\ Magdy Mamdouh Elbordiny ${ }^{4}$, Zaid ,Samy Abou Zaid ${ }^{5}$ \\ 1,2,3,5 Obstetrics and Gynaecology Department, Elshatby University Hospital, Alexandria, Egypt \\ ${ }^{4}$ Clinical Pathology Department, Faculty of Medicine, Alexandria University, Egypt \\ Corresponding Author \\ Dina, Medhat Shalaby \\ Department of Obstetrics and Gynaecology, Elshatby University Hospital, Alexandria, Egypt \\ Email-dina-shalaby@live.com.Phone:+201015111450,+97433221897
}

\begin{abstract}
The present study was undertaken to investigate the prevalence of thrombophilia-associated gene mutations (factor V Leiden,prothrombin gene G20210A and methylene-tetrahydrofolate reductase MTHFR C677T) in relation to recurrent miscarriage. Two hundred pregnant women divided into two groups were included in the study. Group I included 100 women with history of $\geq 3$ unexplained consecutive pregnancy losses and group II included 100 agematched controls with no history of recurrent miscarriage. Blood samples were collected from all pregnant women enrolled in the study for DNA extraction and genotype analysis based on polymerase chain reaction and reverse hybridization. Factor $V$ Leiden and prothrombin gene mutations did not differ significantly between groups, whereas, MTHFR C677T mutations and combined thrombophilias (Factor V Leiden and MTHFR C667T) were significantly increased in group I compared to controls. Moreover, the total prevalence of gene mutations was significantly increased in group I (61\%) compared to controls $(21 \%)$. Homozygosity and heterozygosity did not differ significantly between groups, however, in group I, heterozygotes were significantly increased compared to homozygotes for each of the three gene mutations studied.
\end{abstract}

Keywords: Recurrent miscarriage, thrombophilia, factor V Leiden, prothrombin gene G20210A, methylenetetrahydrofolate reductase.

\section{INTRODUCTION}

Pregnancy loss is a common occurrence among reproductive age women. Whereas, approximately $15 \%$ of all clinically recognized pregnancies result in spontaneous loss, there are many more pregnancies that fail prior to being clinically recognized. Only $30 \%$ of all conceptions result in a livebirth. ${ }^{[1]}$ 
Recurrent pregnancy loss is defined as three or more consecutive pregnancy losses prior to 20 weeks gestation with an incidence of approximately 1 in 300 pregnancies.2There exists a number of accepted etiologies for RPL including parental chromosomal abnormalities, untreated hypothyroidism, uncontrolled DM,uterine anatomic abnormalities, and antiphospholipid antibody syndrome. Other possible etiologies include additional endocrine disorders, heritable and/or acquired thrombophilia, immunologic abnormalities, infections and environmental factors. ${ }^{[2],[3]}$

Evidence addressed the association of inherited thrombophilia with recurrent pregnancy loss, focusing on tests for three genetic variants; factor V Lieden, prothrombin G 20210A and methylenetetrahydrofolate reductase(MTHFR).4 Associations between these heritable thrombophilia variants and other serious pregnancy complications as fetal growth restriction, placental abruption, preeclampsia, eclampsia, prematurity and intrauterine fetal death have also been documented.5 The main underlying mechanisms seem to be inhibition of trophoblast differentiation/ invasion, and thrombosis of the maternal side of the placenta resulting in placenta mediated pregnancy complications and fetal loss. ${ }^{[6],[7]}$

Factor $\mathrm{V}$ Leiden mutation is a point mutation in the gene for clotting factor V. It has an autosomal dominant inheritance and is the most common inherited form of thrombophilia, with a prevalence in the general population ranging from $1-15 \%$.It is a genetic disorder characterized by poor anticoagulant response to activated protein $\mathrm{C}$ and is the most common inherited mutation associated with increased risk of thromboembolism (VTE). ${ }^{[8]}$

The prothrombin G20210A has a prevalence of $2-5 \%$ in the general population. Although less frequent than factor $\mathrm{V}$ Leiden,it is detected in up to $17 \%$ of pregnant patients with VTE. Compared with women with only prothrombin G20210A mutation, those with combined thrombophilia have a threefold greater risk of VTE. Double heterozygosity for both factor $\mathrm{V}$ Leiden and prothrombin gene mutation occurs in approximately 1 in 1000 in the general population and in $1-3 \%$ of pregnant women with VTE. ${ }^{[9],[10]}$

Hyperhomocysteinemia is another thrombophilic anomaly which may be genetic or acquired and has been proposed as a potential cause of recurrent miscarriage. The most common form of genetic hyperhomocysteinemia results from C667 $\mathrm{T}$ polymorphism in the methylene-tetrahydrofolate reductase (MTHFR) gene.Suggested pathophysiologic mechanisms for the effects of homocysteine include increased peroxidation injury, direct effect on endothelial cells, promotion of monocytic chemotaxis, promotion of clotting and activation of platelet aggregation. ${ }^{[11],[12]}$

However, the relationship between thrombophilia associated gene mutations and adverse obstetric outcome is controversial and data in the literature are inconsistent because of study heterogeneity, potential publication bias and sequential testing. [13],[14],[15]

\section{OBJECTIVE OF THE STUDY}

To investigate the prevalence of thrombophilia associated gene mutations namely,factor $\mathrm{V}$ (Leiden), prothrombin G20210A and methylene-tetrahydrofolate 
reductase $\mathrm{C} \quad 667 \mathrm{~T}$ ) in relation to recurrent miscarriage in an attempt to identify candidates for anticoagulation to improve pregnancy outcome.

\section{MATERIAL AND METHODS}

A case-control study was conducted on 200 pregnant women between 9 -34 weeks of gestation attending the antenatal outpatient clinic for routine follow up. The study was undertaken to determine the prevalence of factor $\mathrm{V}$ Leiden,prothrombin G20210A and methylene -tetrahydrofolate reductase C667T in relation to recurrent miscarriage. All patients signed an informed consent to declare their agreement to be enrolled in the study, as agreed upon by the Research Ethics Committee.

\section{INCLUSION CRITERIA}

Group I:included 100 pregnant women with a history of three or more unexplained consecutive pregnancy losses.

Group II: included 100 healthy age matched pregnant women with no history of recurrent miscarriages.

\section{EXCLUSION CRITERIA}

1. Induced abortions

2. Infections

3. Systemic diseases

4. Structural uterine anomalies

5. Personal or family history of thromboembolism.

All patients (group I and group II) were subjected to the following:-
1. Thorough
history
taking including:-
- Age
- Gestational age
- Number and outcome of previous pregnancies

- Number of previous miscarriages

- Miscarriage stage (first or second trimester)

2. Physical examination

3. Ultrasound for fetal viability and gestational age.

4. Patients in group I (history of $\geq$ unexplained recurrent miscarriages) were selected based on complete work-up undertaken prior to pregnancy to exclude a cause for recurrent miscarriage and included the following investigations:-

- Fasting blood sugar.

- Hormonal assays:FSH,LH,prolactin and thyroid function tests.

- Anticardiolipin antibodies and lupus anticoagulant.

- Hysterosalpingography and /or hysteroscopy for the uterine cavity

- Karyotyping for chromosomal aberrations in both partners

- TORCH screening

- Transvaginal ultrasound for ovarian morphology.

5. Blood samples were collected from all pregnant women enrolled in the study for DNA extraction and genotype analysis. Factor V Leiden, prothrombin (PTH) and MTHFR gene mutations were assayed based on polymerase chain reaction (PCR) and reverse hybridization. The frequency of homozygous and heterozygous gene mutations, as well as, the coexpression of mutations were determined.

\section{Analysis for Factor V-PTH-MTHFR mutations}

The assay is based on the reverse hybridization principle and included three successive steps utilizing a commercially available kit. 


\section{JMSCR Vol||04||Issue||04||Page 10114-10125||April}

\section{- DNA Extraction}

DNA was extracted from anticoagulated whole blood .Extraction started by incubating the blood and Lysis solution for 15 min followed by a binding step using the GENXTRACT Resin and another incubation as per the manufacturer guidelines.

\section{- Multiplex PCR}

- Factor V Leiden, prothrombin and MTHFR gene sequences were simultaneously amplified in vitro and biotin labeled in a single (multiplex) amplification reaction.

- The amplification products were selectively hybridized to a test strip which contained oligonucleotide probes (wild type and mutant specific) immobilized as parallel lines.
- Bound biotinylated sequences were detected using streptavidinalkaline phosphatase and colour substrates.

- The assay covered three mutations namely, Factor V (G1691A), prothrombin (G20210A) and MTHFR (C677T) and the results were reported as normal genotype, heterozygous genotype or homozygous mutant genotype.

\section{STATISTICAL METHODS}

Data were analyzed using IBM SPSS Software 20.0.Mean, standard deviation, Chi-square test,t-test and Mann-Whitney tests were calculated using standard formulae. P value $<0.05$ was considered significant.

\section{RESULTS}

Table 1: Comparison between groups as regards age

\begin{tabular}{|c|c|c|}
\hline Age (years) & $\begin{array}{lll}\begin{array}{l}\text { Group } \\
\text { group) }\end{array} & \text { I } & \text { (study } \\
\end{array}$ & Group II ( controls) \\
\hline Range & $23-36$ & $24-37$ \\
\hline Mean & 28.65 & 27.61 \\
\hline S.D. & 9.82 & 8.65 \\
\hline T- test & \multicolumn{2}{|c|}{0.85} \\
\hline $\mathrm{P}$ significance value & \multicolumn{2}{|c|}{0.42} \\
\hline
\end{tabular}

The age of patients in group I ranged from 23 to with a mean age of $27.61 \pm 8.65$ years. There was 36 years with a mean age of $28.65 \pm 9.82$ years, whereas, in group II the range was 24 to 37 years

Table 2: Comparison between groups as regards total number of pregnancies, gravidity and parity

\begin{tabular}{|l|l|l|c|}
\hline & Group I & Group II & P value \\
\hline $\begin{array}{l}\text { Total number of } \\
\text { pregnancies } \\
\text { (live births +abortions) }\end{array}$ & 421 & 390 & 0.743 \\
\hline Gravidity & $3-9$ & & \\
Range & 6.25 & $2-5$ & $0.002^{*}$ \\
Mean & 2.01 & 3.25 & \\
S.D. & & 1.89 & \\
\hline Parity & $1-4$ & $1-4$ & 0.087 \\
Range & 2.01 & 2.68 & \\
Mean & 1.36 & 1.04 & \\
S.D. & & \\
\hline
\end{tabular}




\section{JMSCR Vol||04||Issue||04||Page 10114-10125||April}

The total number of pregnancies in group I were 421 compared to 390 in controls. There was no significant difference between groups.. Gravidity in group I ranged from 3-9 with a mean of $6.25 \pm 2.01$, whereas, in group II the range was $2-5$ with a mean of $3.25 \pm 1.89$. There was a significant increase in gravidity in group I compared to group II $(\mathrm{p}=0.002)$. However, parity in group I and II ranged from 1- 4 with a mean of $2.01 \pm 1.36$ and $2.68 \pm 1.04$ respectively. There was no significant difference between groups.

Table 3: Comparison between groups as regards gestational age

\begin{tabular}{|l|c|c|}
\hline Gestational age (weeks) & Group I & Group II \\
\hline Range & $9-34$ & $12-33$ \\
Mean & 24.3 & 21.4 \\
S.D. & 5.9 & 9.85 \\
\hline T test & 1.25 & \\
P significance value & 0.236 & \\
\hline
\end{tabular}

In group I, the gestational age at the time of blood sampling ranged from 9-34 weeks with a mean of $24.3 \pm 5.9$ weeks, whereas in group II, the range

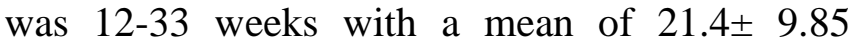
weeks.There was no significant difference between groups.

Table 4: History of live-births and miscarriages in the studied groups

\begin{tabular}{|l|l|l|l|}
\hline & Group I & Group II & P value \\
\hline Livebirths & 53 & 370 & \\
Number & 12.5 & 94.8 & $0.001^{*}$ \\
\% out of total pregnancies & & & \\
\hline Miscarriages & 368 & 20 & $0.001^{*}$ \\
Number & $231(62.7 \%)$ & $11(55 \%)$ & 0.211 \\
First trimester & $137(37.3 \%)$ & $9(45 \%)$ & 0.107 \\
Second trimester &
\end{tabular}

The number of livebirths in group I was 53 compared to 370 in group II. There was a statistically significant difference between groups $(p=0.001) . F u r t h e r m o r e$, there was a statistically significant difference between groups as regards the total number of miscarriages.

Table 5: Prevalence of thrombophilia polymorphisms in the studied groups

\begin{tabular}{|l|l|l|l|}
\hline & Group I & Group II & P value of mean \\
\hline Factor V Leiden & 13 & 10 & 0.562 \\
\hline Prothrombin gene G20210A & 6 & 2 & 0.412 \\
\hline MTHFR C677T & 42 & 8 & $0.001^{*}$ \\
\hline Total & 61 & 20 & $0.003^{*}$ \\
\hline
\end{tabular}

Considering each gene mutation
individually, the prevalence of Factor $\mathrm{V}$ Leiden and prothrombin G20210A mutations did not differ significantly between groups, whereas, MTHFR C677T mutation and the total prevalence of the three gene mutations was significantly increased in group I. 
Table 6: Analysis of thrombophilia gene mutations in the studied groups

\begin{tabular}{|c|c|c|c|c|c|}
\hline & \multicolumn{2}{|c|}{ Group I } & \multicolumn{2}{|c|}{ Group II } & $\mathrm{P}$ value \\
\hline & Number & $\%$ & Number & $\%$ & \\
\hline $\begin{array}{l}\text { Factor V Leiden } \\
\text { Heterozygous } \\
\text { Homozygous }\end{array}$ & $\begin{array}{l}11 \\
2\end{array}$ & $\begin{array}{l}84.6 \\
15.4\end{array}$ & $\begin{array}{r}10 \\
0\end{array}$ & $\begin{array}{c}100 \\
0\end{array}$ & 0.187 \\
\hline $\begin{array}{l}\text { Prothrombin gene G20210A } \\
\text { Heterozygous } \\
\text { Homozygous }\end{array}$ & $\begin{array}{l}6 \\
0\end{array}$ & $\begin{array}{l}100 \\
0\end{array}$ & $\begin{array}{l}2 \\
0\end{array}$ & $\begin{array}{c}100 \\
0\end{array}$ & \\
\hline $\begin{array}{l}\text { MTHFR C667T } \\
\text { Heterozygous } \\
\text { Homozygous }\end{array}$ & $\begin{array}{l}39 \\
3\end{array}$ & $\begin{array}{l}92.8 \\
7.1\end{array}$ & $\begin{array}{l}9 \\
0\end{array}$ & $\begin{array}{c}100 \\
0\end{array}$ & 0.426 \\
\hline Combined Factor V Leiden and MTHFR & 10 & 16.4 & 0 & 0 & $0.032 *$ \\
\hline
\end{tabular}

Homozygosity and heterozygosity for each of the gene mutations studied did not differ significantly between groups.No homozygosity was detected for the prothrombin gene mutation nor for any gene mutation in group II.However, there was a

significant difference between groups as regards combined thrombophilia involving Factor V Leiden and MTHFR C677T gene mutations.10 cases were detected in group I and none in group II.

Table 7: Analysis of thrombophilia gene mutations in group I

\begin{tabular}{|l|c|l|l|l|l|l|}
\hline & \multicolumn{2}{l|}{ Heterozygous } & \multicolumn{2}{l|}{ Homozygous } & \multicolumn{2}{l|}{ Total } \\
\hline & Number & $\%$ & Number & $\%$ & Number & $\%$ \\
\hline Factor V Leiden & 11 & 84.6 & 2 & 15.4 & 13 & 13 \\
\hline $\begin{array}{l}\text { Prothrombin } \\
\text { gene G20210A }\end{array}$ & 6 & 100 & 0 & 0 & 6 & 6 \\
\hline MTHFR C677T & 39 & 92.8 & 3 & 7.1 & 42 & 42 \\
\hline $\begin{array}{l}\text { X2 } \\
\text { P }\end{array}$ & \multicolumn{7}{|c|}{$\begin{array}{l}12.65 \\
0.013^{*}\end{array}$} \\
\hline
\end{tabular}

Homozygosity and heterozygosity were assessed for each of the three gene mutations studied and compared in group I.Heterozygotes were significantly increased compared to homozygotes.

\section{DISCUSSION}

Pregnancy is considered an acquired hypercoaguble state due to increased levels of coagulation factors, decreased levels of anticoagulants and decreased fibrinolytic activity. ${ }^{16}$ The gradual increase in hypercoagulability during normal pregnancy predisposes to VTE and to gestational vascular complications including recurrent pregnancy loss, intrauterine growth restriction, eclampsia, preeclampsia and placental abruption. These adverse pregnancy outcomes affect up to $15 \%$ of gestations and are the major cause of maternal and fetal morbidity and mortality. [17],[18]

Pregnancy loss is a common medical problem among reproductive age women. However, relatively few women having one pregnancy loss experience multiple or recurrent pregnancy loss. ${ }^{1}$ Mounting evidences point to a link between inherited thrombophilia and recurrent fetal loss being associated with abnormal placental vasculature and disturbances of haemostasis leading to inadequate fetomaternal circulation. ${ }^{[19]}$

This case-control study was conducted on 200 pregnant women divided into two groups .Group I included 100 pregnant women with a history of three or more unexplained consecutive miscarriages and 
group II included 100 healthy agematched pregnant women with uncomplicated previous pregnancies.

In the present study, maternal age did not differ significantly between groups $(p=0.42)$. However, gravidity in group I was significantly increased compared to controls $(p=0.002)$, whereas, the total number of pregnancies, parity and the gestational age at the time of blood sampling did not differ significantly between groups $(p=0.743,0.08$ and 0.236 respectively).

As regards the history of live births and previous abortions in the study groups, there was a significant increase in the number of live births per woman among controls and a significant increase in the total number of miscarriages among the patients group.

On assessing the individual prevalence of thrombophilia polymorphisms in the studied groups, it was found that Factor $\mathrm{V}$ Leiden and prothrombin gene G20210A mutations individually did not differ significantly between those with a history of recurrent miscarriage and controls. There is a large and contradictory body of literature on the association between maternal inherited thrombophilia and recurrent miscarriage $\mathrm{e}^{[8],[9],[20]}$. Although most [8],[21],[22] but not all1 ${ }^{[8],[23]}$ large prospective cohort studies have failed to establish a consistent association between inherited thrombophilia and early or late fetal loss, case -control and retrospective cohort studies have generally reported a link between factor V Leiden heterozygosity and possibly prothrombin gene mutation heterozygosity and fetal loss after 10 weeks and particularly for non recurrent loss after 20 weeks [14],[24],[25].This suggests that any association is limited to high risk populations and is modest. Small case- control or retrospective cohort studies involving heterogeneous populations have frequently reported contradictory results, in part because of the influence of various confounders (e.g. age, obesity) that are often not analyzed appropriately [14],[25].

In our study, MTHFR C 667T mutations were significantly increased in the patients group compared to controls. Several studies, [26],[27],[28] reported increasing evidence for a pathogenetic role of MTHFR gene polymorphism C677T in recurrent pregnancy loss, in particular, early loss. On the other hand, several authors [29],[30] found a negative association stating that MTHFR polymorphisms do not carry any risk in pregnancy. The different inclusion criteria and the different ethnic backgrounds of the selected patients may have contributed to the contradictory results.

In the current study, the total prevalence of the three gene mutations namely, Factor V Leiden, prothrombin gene G20210A and MTHFR C677 $\mathrm{T}$ were significantly increased in the patients group compared to controls. This is in accordance with some previous studies [30],[31],[32]. However, other large prospective studies $[8],[21],[22]$ reported contradictory results stating that hypercoagulable thrombophilic gene mutations are not increased in women with recurrent miscarriage.

Infact, case- control and cohort studies reflect methodological diversity and clinical heterogeneity. Studies have been conducted in different countries, using different study designs and in routine care settings,as well as, high risk referral centres. Study limitations have included inadequately described and /or heterogeneous case and control groups and cohorts, insufficient information to adequately assess potential biases, and missing or incomplete information on 
important covariates as maternal age and number and timing of losses.

In our study, there was a significant increase in the number of cases with combined thrombophilia in the patients group compared to controls. Combined thrombophilia included Factor V Leiden and MHTFR C677T and none of the cases involved prothrombin gene G20210A mutation. The same results were reported by previous studies [17],[26],[33],[34] that identified combined thrombophilic defects in women with recurrent pregnancy loss, both early and late. The study by RozanoGorelick et al 17 reported that combined thrombophilia exists when inherited and /or acquired prothrombotic factors are pooled and every combination carries a different risk of thrombosis. Furthermore, Sarig et al 18 proposed a scoring system for women with thrombophilia based on four major categories: obstetric history, previous thromboembolic events, family history of thrombosis or gestational vascular complications and type of thrombophilia. Combined thrombophilia was given a high score and subclassified as combined moderate ( heterozygous for both factor $\mathrm{V}$ Leiden and prothrombin G20210A mutations) and combined severe (strong lupus anticoagulant and homozygous for factor $\mathrm{V}$ Leiden or antithrombin deficiency). The total score is calculated by summing up the scores of the four categories. Based upon the score achieved, the pregnancy risk for an individual woman may be stratified into four levels of risk: low $\leq 5$, intermediate (score 6-10), high (score 11-14) and extremely high (score $\geq 15)$.

Finally, the number of homozygous and heterozygous individuals were assessed for each of the gene mutations studied and compared between groups. No homozygosity was detected in controls and heterozygotes were significantly increased in the patients group compared to homozygotes. Couto et al35 reported a low prevalence of homozygotes for factor $\mathrm{V}$ Leiden and stated that the prothrombotic tendency during pregnancy and the risk of thromboembolic events is increased with antithrombin deficiency and homozygous factor V Leiden as single traits.Infact, the reported prevalence in the general population of factor $V$ Leiden and prothrombin gene homozygotes is less than $1 \%$ with $2-4 \%$ risk of VTE per pregnancy increasing to around $17 \%$ in women with a previous history of VTE13,36.

Hence, our study and similar studies reported an association between some types of thrombophilia and recurrent miscarriage, but the absolute risk is small and varies considerably among reports. However, most large prospective cohort studies have failed to establish a consistent association between inherited thrombophilia and adverse pregnancy outcome.

According to recent evidence [13],[37], screening for inherited thrombophilia in women with a history of recurrent or non recurrent fetal loss, abruption, intrauterine growth restriction, or preeclampsia is not recommended. Moreover, there is mounting evidence that administration of prophylactic anticoagulation during pregnancy for the prevention of placentamediated pregnancy complications does not improve pregnancy outcome in affected patients.

\section{CONCLUSIONS}

The prevalence of Factor $\mathrm{V}$ Leiden and prothrombin gene G20210A mutations did not differ significantly between those with history of recurrent miscarriage and controls. 
MTHFR C667T mutations and the total prevalence of the three gene mutations were significantly increased in the patients group compared to controls.

There was a significant increase in the prevalence of combined thrombophilia (Factor V Leiden and MTHFR C677T) in the patients group compared to controls.

Combined thrombophilia did not involve prothrombin gene G20210A mutations in either group.

No homozygosity was detected in controls for any of the gene mutations studied.

Heterozygotes were significantly increased in the patients group compared to homozygotes.

\section{SUMMARY}

Recurrent pregnancy loss is multifactorial involving clinical and biological risk factors. Evidence addressed the association of inherited thrombophilia with recurrent pregnancy loss and other serious pregnancy complications. However, the relation between thrombophilia associated gene mutations and adverse obstetric outcome is controversial and data in the literature are inconsistent.

The aim of the present study was to investigate the prevalence of thrombophilia gene mutations, namely, factor V Leiden, prothrombin G20210A and methylenetetrahydrofolate reductase C667T in relation to recurrent miscarriage. This case-control study was conducted on 200 pregnant women divided into two groups. Group I included 100 pregnant women with history of three or more unexplained consecutive miscarriages and group II included 100 healthy age-matched pregnant women with uncomplicated previous pregnancies. Blood samples were collected from all pregnant women enrolled in the study for DNA extraction and genotype analysis based on polymerase chain reaction and reverse hybridization. The assay covered three mutations, factor $\mathrm{V}$ Leiden, prothrombin gene G20210A and MTHFR C667T.

The prevalence of Factor $\mathrm{V}$ Leiden and prothrombin gene $\mathrm{G} 20210 \mathrm{~A}$ mutations did not differ significantly between those with history of recurrent miscarriage and controls. However, MTHFR C667T mutations and the total prevalence of the three gene mutations were significantly increased in the patients group compared to controls.

There was a significant increase in the prevalence of combined thrombophilia (Factor V Leiden and MTHFR C677T) in patients group compared to controls. However, combined thrombophilia did not involve prothrombin gene G20210A mutations in either group.

Finally, the number of homozygous and heterozygous individuals were assessed for each of the gene mutations studied. No homozygosity was detected in controls and heterozygotes were significantly increased in the patients group compared to homozygotes.

\section{B IBLIOGRAPHY}

1. A.J.Wilcox, C.R.Weinberg, J.F.O' Connor, et al,Incidence of early loss of pregnancy.N Engl J Med, 319(4),pp.189-194, 2000.

2. O.B.Christian, R.Steffensen, H.S. Nielsen and K.Varming, Multifactorial etiology of recurrent miscarriage and its scientific and clinical implications.Gynecol Obstet Invest,66,pp.257-267, 2008.

3. J.E.Warren, R.M.Silver.Genetics of pregnancy loss.Clin Obstet Gynecol, 51,pp.84-95,2008.

4. M.A.Rodger, M.Paidas, C. Mclintock, et al, Inherited thrombophilia and pregnancy complications re- 
visited. Obstet Gynecol,112, pp.320,2008

5. J.M.Said, J.R.Higgins, E.K.Moses, et al, Inherited thrombophilia polymorphisms in pregnancy outcomes in nulliparous women. Obstet Gynecol,115,pp.5, 2010

6. L.Robertson, O.Wu,P. Langhorne, et al.Thrombophilia in pregnancy; a systematic review.Br J Haematol, 132,pp.171,2006.

7. M.J.Kupfermine.Thrombophilia and pregnancy.Reprod Biol Endocrinol,1,pp.111,2003.

8. D.Dizon-Townson, C. Miller, B.Sibai, et al.The relationship of factor $V$ Leiden mutation and pregnancy outcomes for mother and fetus.Obstet Gynecol,106,pp.517$524,2005$.

9. R.M.Silver,Y.Zhao, C.Y. Spong, et al. Prothrombin gene G20210A mutation and obstetric complications. Obstet Gynecol,115, pp. 14,2010.

10. M.D.McColl, J.Ellison, F.Reid, et al.Prothrombin 20210G-A, MTHFR C667T mutations in women with venous thromboembolism associated with pregnancy.BJOG, 107,pp.565,2000.

11. B.T.Zhu.On the mechanism of homocysteine pathophysiology and pathogenesis: a unifying hypothesis. Histol Histopathol,17,pp.12831291,2002.

12. R.P.Murphy,C. Donoghue, R.J. Nalten, et al. Prospective evaluation of the risk conferred by factor $\mathrm{V}$ Leiden and thermolabile methylene tetrahydrofolate reductase polymorphisms in pregnancy. Arterioscler Thromb Vas Biol, 20,pp.266, 2000.
13. C.H.J.Lockwood,

K.A.Bauer, L.K.Leung, S.M.Ramin, et al. Inherited thrombophilias in pregnancy.Up To Date, Dec, 2015
14.
L.Robertson,
$\mathrm{O} . \mathrm{Wu}, \mathrm{P}$.

Langhorne, et al.Thrombophilia in pregnancy: a systemic review. $B r J$ Haematol ,132,pp.171,2006.

15. S.Bouvier,E.Cochery-

Nouvellon, G.Lavigne-Lissalde, et al. Comparative incidence of pregnancy outcomes in thrombophilia positive women from NOH-APS observational study. Blood, 123,pp.414,2014.

16. M.J.Kupfermine.Thrombophili a and pregnancy.Reprod Biol Endocrinol, 1,pp.111,2003

17. A.Rozano-Gorelick, E. Papadakis, B.Brenner. Combined thrombophilia and obstetric complications.Open Athero Thromb $J, 2, p p .38-41,2009$.

18. G.Sarig, G.Vidergor, B. Brenner. Assessment and masnagement of high risk pregnancies in women with thrombophilia. Blood Rev,23 (4),pp. 143-147,2009.

19. I.A.Greer.The challenge of thrombophilia in maternal-fetal medicine.N Engl $J \quad$ Med ,342,pp.424,2000.

20. M.A.Rodger, M.T.Betancourt, P.Clark, et al.The association of factor $V$ Leiden and prothrombin gene mutation and placenta mediated pregnancy complications: a systemic review and meta analysis of prospective cohort studies. PLOS Med,7(6), pp.e1000292, 2010.

21. H.Roque, M.J.Paidas, E.F. Funai, et al.Maternal thrombophilias are not associated with early 
pregnancy loss.Thromb Haemost, 91,pp.290,2004.

22. P.Clark, I.D.Walker,L.Govan , et al.The GOAL study: a prospective examination of the impact of factor $\mathrm{V}$ Leiden and ABO blood groups on haemorrhagic and thrombotic pregnancy outcomes. Br J Haematol, 140,pp.236, 2008.

23. F.E.Preston, F.R.Rosendaal, I.D.Walker, et al.Increased fetal loss in women with heritable thrombophiliaL. Lancet ,348,pp.913,1996.

24. U.Kjellberg, M.Van Rooijen, K. Bremme,M.Hellgren.Factor V Leiden mutation and pregnancy related complications. Am J Obstet Gynecol, 203,pp.469-468,2010.

$25 . \quad$ S.Bouvier,E.Cochery-

Nouvellon, G.Lavigne-Lissalde, et al. Comparative incidence of pregnancy outcomes in thrombophilia positive women from $\mathrm{NOH}-$ APS observational study. Blood,123,pp.414,2014.

26. P.Di Mico,M.D'Uva.Recurrent pregnancy loss and thrombophilia.Open Atherosclerosis \&Thrombosis J,2,pp.33-35,2009.

$27 . \quad$ A.Lissak,

A.Sharon, O.Fruchter, A.Kassel, et al. Polymorphism for mutation of cytosine to thymine location 677 in the methylene-tetrahydrofolate reductase gene is associated with recurrent early pregnancy loss. Am $J$ Obstet Gynecol, 181,pp.126$130,1999$.

28. M.G.Wouters,G.H.Boers, H.J. Blom, F.J.Trijbels, C.M.Thomas, et al.Hyperhomocysteinemia: a risk factor in women with unexplained recurrent early pregnancy loss.Fertil Steril,60,pp.820-825,1993.
29.

A.Makino,

T.Nakanishi, M.Sugiura-Ogasawara, ,Y.Ozaki, N.Suzumori, K.Suzumori. No association of C667T methylenetetrahydrofolate reductase and an endothelial nitric oxide synthase polymorphism with recurrent pregnancy loss.Am $J$ Reprod Immunol ,52,pp.60-66,2004.

30. A.Ren, J.Wang. MTHFR C677T polymorphism and the risk of unexplained recurrent pregnancy loss: a meta-analysis.Fertil Steril,86,pp.1716,2006.

31. M.Aksoy,I.Tek,H.Karabulut,B. Berker,F.Soylemez.The role of thrombophilia related to factor $\mathrm{V}$ and factor II G20210A mutations in recurrent abortions. $J$ Pak Med Assoc ,55,pp.104-108,2005.

32. A.Raziel,Y.Kornberg,S.Friedle $r$, et al.Hypercoaguble thrombophilic defects and hyperhomocysteinemia in patients with recurrent pregnancy loss.Am J Reprod Immunol,45,pp.6571,2001 .

33. C.B.Coulam,R.S.Jeyendran,A.

L.Fishel,R.Roussev.Multiple

thrombophilic gene mutations rather than specific gene mutations are risk factors for recurrent miscarriage .Am $J \quad$ Reprod Immunol,55,pp.360$380,2006$.

34. H.Mandel,B.Brenner,M.Berant .Co-existence of hereditary homocysteinemia and factor $\mathrm{V}$ Leiden-effect on thrombosis.N Engl J Med,348,pp.763-768,1996.

35. E.Couto,M.L.Nomura,R.Barini J.L.Pinto.Silva.Pregnancy associated venous thromboembolism in combined heterozygous factor V Leiden and prothrombin G20210A mutations.Sao Paulo Med $J, 123(6)$ :pp.286-288,2005. 
36. R.B.Zotz,

A.Gerhtardt,

R.E.Scharf.Inherited thrombophilia and gestational venous thromboembolism. Best Pract Res Clin Haematol, 16,pp.243, 2003.

37. American College of

Obstetricians and Gynaecologists Women Health Care Physicians. ACOG Practice Bulletin no 138:Inherited thrombophilias in pregnancy.Obstet Gynecol,122,pp.706-717,2013. 